\title{
Organization of railway track tamping work using the software and hardware complex SMTC
}

\author{
Aleksey Manakov ${ }^{1, *}$, Sergey Kolarzh ${ }^{1}$, and Aleksey Mashkov ${ }^{2}$ \\ ${ }^{1}$ Siberian Transport University, Dusi Kovalchuk st. 191, Novosibirsk, Russia \\ ${ }^{2}$ JSC "Russian Railways", Directorate for the operation of track machines of the Central Infrastructure \\ Directorate - a branch of JSC "Russian Railways", Russia
}

\begin{abstract}
The main purpose of this work is to study the applicability of the hardware and software complex "Monitoring system for the technical condition of track equipment" to monitor the performance of track operations. The methodological base of study is formed on the basis of the analysis of scientific works of domestic and foreign scientists and the systematization of statistical data on the organization of the system of technical operation of track machines at enterprises of the West Siberian Railway. As a result of the study, it was proved that the functional of the system for remote monitoring of the technical condition of track equipment, which was developed by the specialists of the Siberian State Transport University, allows for continuous monitoring of the performance of track operations. Quality control of works is carried out on the basis of an estimation of parameters of functioning of working elements of the track equipment involved in the process of work performance. The application of the developed software and hardware complex allows significantly reducing the financial losses of railway transport enterprises associated with the repeated performance of track operations. The problems to be solved with the help of the proposed control system correspond to the priority areas of the Strategy for the Development of Railway Transport in the Russian Federation until 2030 in the development and implementation of means for automating control of infrastructure.
\end{abstract}

\section{Introduction}

The large-scale transformation in JSC "Russian Railways", which allowed for optimization of the company's management system, could not but affect the railway track complex. For example, work on the repair of track equipment was outsourced to JSC "Kaluga Plant «Remputmash»". The result of this separation of responsibility areas was the emergence of the need for tools for monitoring the technical parameters of track machines, both during operation and after repair and preventive measures, at the enterprises operating this equipment. In addition, the operation of equipment, the technical parameters of which

\footnotetext{
*Corresponding author: manakov005@mail.ru
} 
do not correspond to the nominal values, may lead to the need for repeated repairs. According to experts of the West Siberian Railway, the average annual volume of repeated repairs is $40 \%$ in relation to the planned volume.

With the purpose of determining the intensity of the occurrence of failures of track equipment in the period of summer track works, experts of the department "Technology of transport engineering and machine operation" carried out a study of the distribution of failures of 10 types of track machines by the months of summer track works [1]. As a result of the study, it was determined that the significant excess of the average failure rate for most machines falls on the periods of May-June and September-October (Figure 1). The current situation shows that before the work performance in April, the machines undergo the necessary preparation, but failures begin to occur within a month. Further in June, the working capacity of machines is restored, but by September a steady tendency of growth of the failure flow emerges. This situation can be a consequence of two factors: the lack of sufficient exit control after the maintenance and the lack of equipment capable of real-time assessment of the technical condition of the machines and warn of a pre-failure condition.

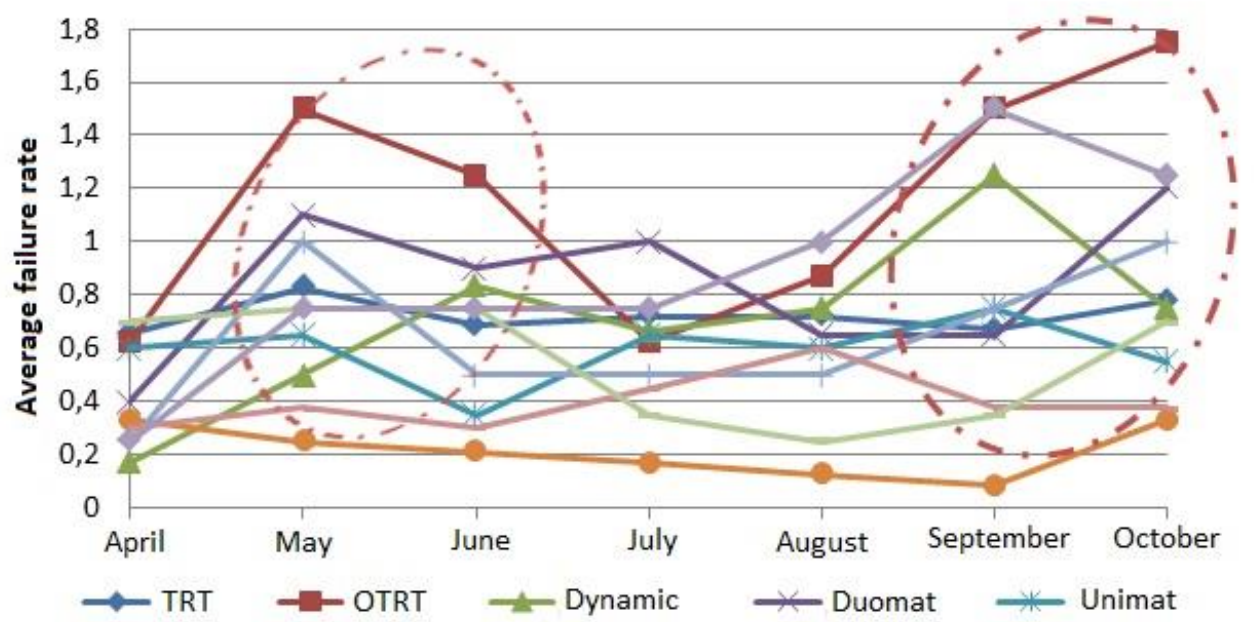

Fig. 1. Distribution of average failure rate of machines by months for the period of summer track works in 2011-2014.

Ensuring the stable operation of machinery is directly related to the control of its technical condition. The more often the control and diagnostic measures are carried out, the greater the probability of its failure-free operation. Of particular importance is the issue of ensuring fail-safe operation for track equipment. This is primarily connected with the fact that the track repair operation is carried out in the "window" mode or in the "closed haul" mode. Both in the first and second case, the equipment failure threatens to disrupt the schedule of works and, as a result, the company's financial losses [1 - 4].

\section{Equipment}

For several years, specialists of the Siberian State University are conducting research in the field of creating a software and hardware complex with the above functions. The result of work in this area was a system for remote monitoring of the technical condition of track equipment [5]. The functional of the system makes it possible to carry out an element-byelement assessment of the eccentric shaft drive of the tamping unit of track machine Duomatic 09-32 without removing it from service. The main parameter of the functioning 
of the working equipment of this machine is the frequency of rotation of the eccentric shaft of the tamping unit. Remote monitoring of this parameter allows for real-time assessment of the technical condition of the tamping unit and the quality of the tamping works.

To monitor the speed of the eccentric shaft on the tamper Duomatic 09-32, the specialists of SSTU installed an on-board terminal used to collect data from primary transducers and two Hall effect sensors measuring the frequency of rotation of the eccentric shafts of the left and right tamping blocks (Figure 2) [6].
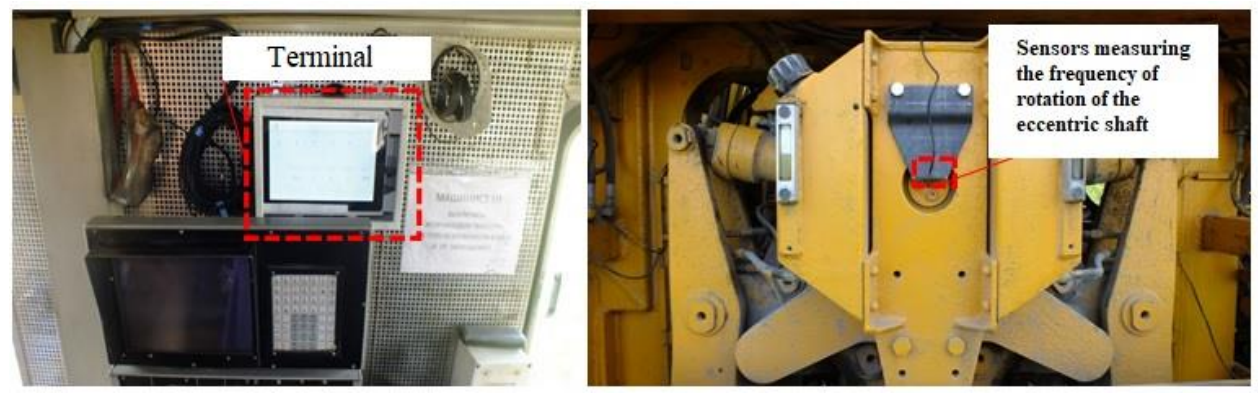

Fig. 2. The on-board terminal and the eccentric shaft speed sensor mounted on the track machine.

The frequency of rotation of the eccentric shaft has a great influence on the quality of tamping. This is evidenced by the results of studies of foreign experts [7].

The frequency of rotation of the eccentric shaft is equivalent to the frequency of the oscillations of the tamping hammers that directly compact the ballast, its deviation from the nominal value, which is in the range of 33-37 Hz. Performing tamping at a frequency of more than $37 \mathrm{~Hz}$ leads to the appearance of the effect of "dilution" of crushed stone (Figure 3 ), while the minimum relative plastic deformation of crushed stone is achieved at frequencies of 33-42 Hz (Figure 4). Tamping of track at a frequency below $33 \mathrm{~Hz}$ and above $37 \mathrm{~Hz}$ ultimately results in a reduction in the period of the stable position of the track panel.

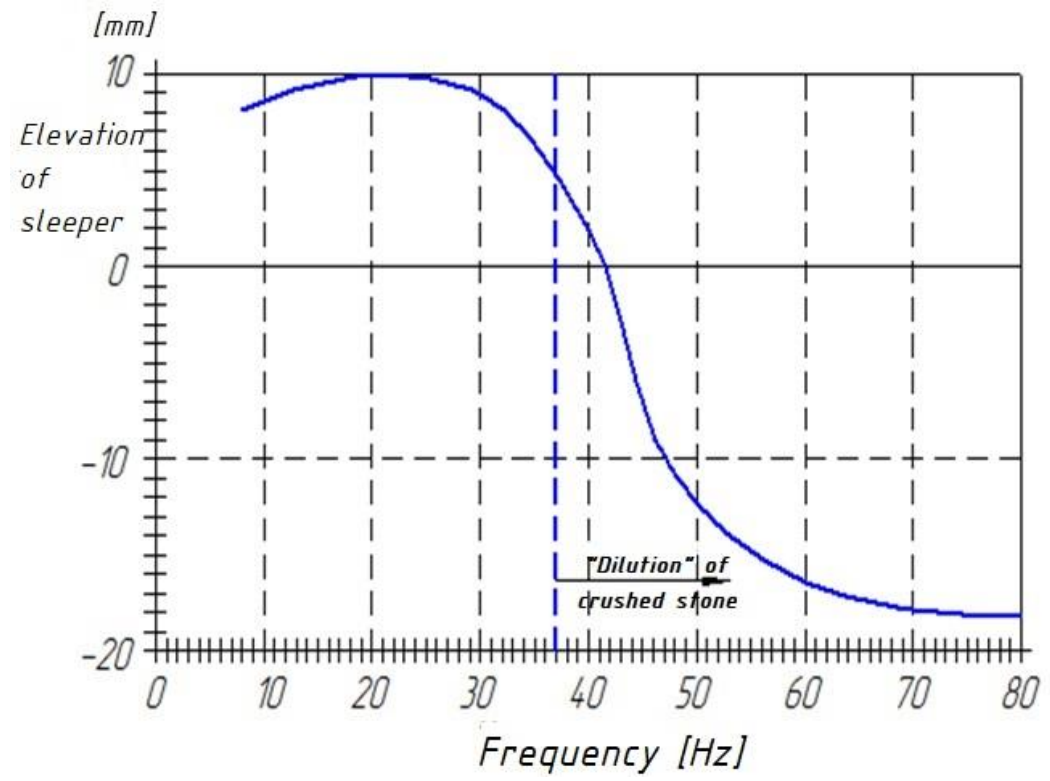

Fig. 3. Influence of the oscillation frequency of the tamping hammers on the effect of "dilution" of crushed stone. 


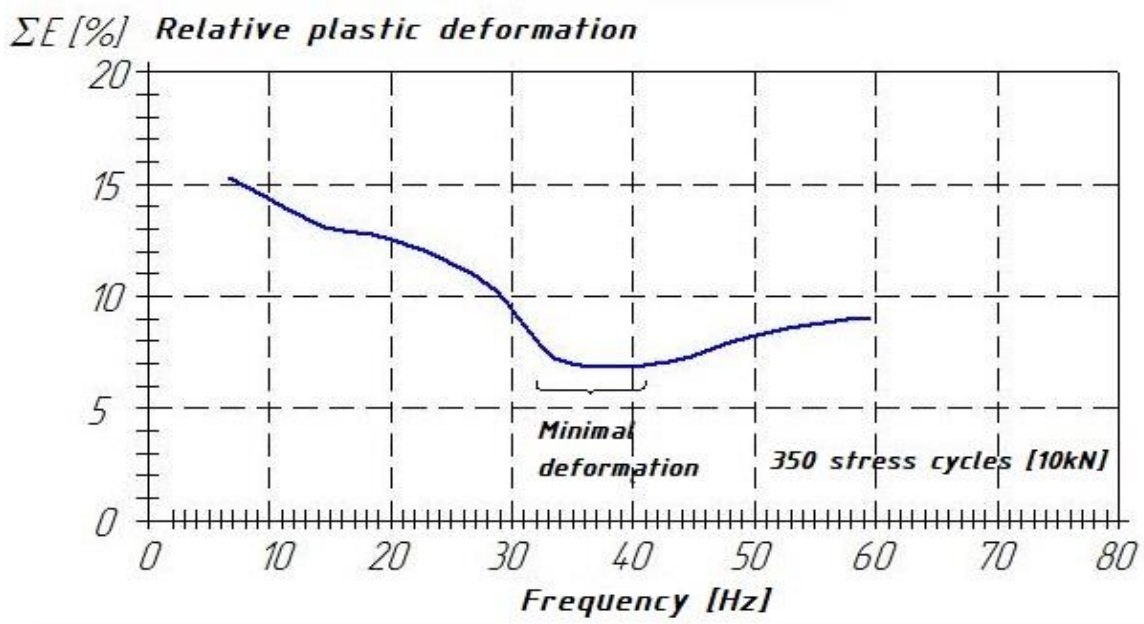

Fig. 4. Influence of the oscillation frequency of the tamping hammers on the relative plastic deformation of crushed stone.

For convenience of presenting information about the current technical condition of the working equipment drive of the Duomatic 09-32 track machine, the coefficient of wear of the tamping unit drive is introduced, which allows obtaining a comprehensive view of the drive status of the eccentric shaft of the tamping unit. Calculation of the coefficient of wear is carried out using the software "MSTC server" developed by the specialists of SSTU.

Calculation of the coefficient $\mathrm{C}_{\mathrm{WHD}}$ assumes the introduction of three correction factors into the formula, which allow taking into account the influence of external factors on the change in the value of the coefficient $\mathrm{C}_{\text {WHD }}$. The formula for calculating the coefficient $\mathrm{C}_{\mathrm{WHD}}$ is as follows:

$$
\mathrm{C}_{\mathrm{WHD}}=100 \%-\left(\mathrm{n}_{\mathrm{M}} /\left[\mathrm{n}_{\mathrm{M}}\right]\right) * \mathrm{k}_{\mathrm{b}} * \mathrm{k}_{\mathrm{th}} * \mathrm{k}_{\mathrm{d}} * 100 \%,
$$

where $n_{M}$ and $\left[n_{M}\right]$ - measured and permissible (normalized) frequency of the shaft of the hydraulic motor $\mathrm{M}, \mathrm{r} / \mathrm{s}$ (or rpm); $\mathrm{k}_{\mathrm{b}}$ - coefficient that takes into account the density of the ballast on which work is performed; $\mathrm{k}_{\text {th }}$ - coefficient that takes into account the wear of the tamping hammers; $k_{d}$ - coefficient that takes into account the frequency of rotation of the drive shaft (if it deviates from the nominal values).

The permissible values of the coefficient $\mathrm{C}_{W H D}$ are calculated on the basis of the following conditions:

1. The permissible range of frequency of rotation of the eccentric shaft is $33-37 \mathrm{r} / \mathrm{s}$.

2. The optimum frequency of rotation of the eccentric shaft is $35 \mathrm{r} / \mathrm{s}$.

3. Correction coefficients $\left(\mathrm{k}_{\mathrm{b}}, \mathrm{k}_{\mathrm{th}}, \mathrm{k}_{\mathrm{d}}\right)$ do not influence the value of the coefficient of $\mathrm{C}_{\mathrm{WHD}}$, i.e. they are equal to one.

Calculation of the coefficient of wear of the working equipment drive $\left(\mathrm{C}_{\mathrm{whd}}\right)$ is based on the data on the frequency of rotation of the eccentric shaft and the drive shaft, which are fixed by the Hall effect sensor, as well as the parameters of ballast density and wear of the tamping hammers, which are chosen by the Duomatic machine operator from the proposed range of values in program "MSTC client" before starting of work.

\section{Results}

As a result of the collection of statistical data for the period of summer track works of 2017 performed by the Duomatic 09-32 track machine at the West Siberian Railway operating 
domain, the values of wear coefficient of the drives of the tamping units were obtained (Figure 5-6).
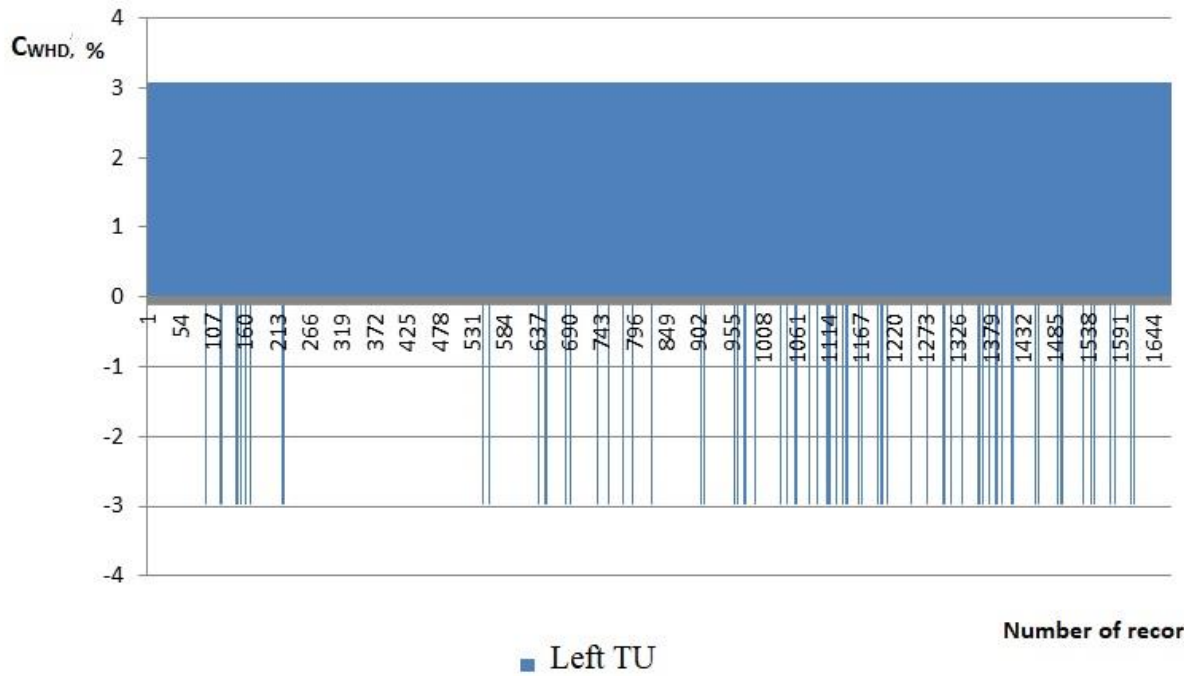

Number of record

Fig. 5. The graph of the coefficient of wear of the hydraulic drive of the eccentric shaft of the left tamping unit.

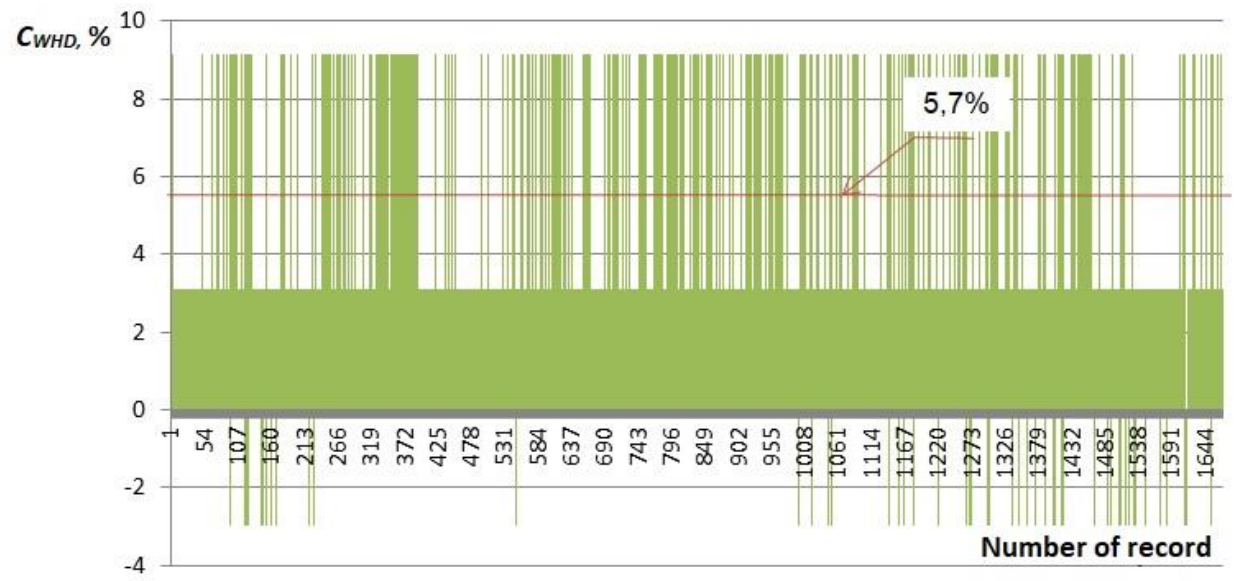

- Right TU

Fig. 6. The graph of the coefficient of wear of the hydraulic drive of the eccentric shaft of the right tamping unit.

From the graphs shown in Figures 5-6, it is evident that the wear coefficient of the hydraulic drive of the eccentric shaft of the left tamping unit is within the allowable range of values. The graph shown in Figure 6 indicates the presence of wear coefficient values exceeding the permissible limit (5.7\%).

To determine the cause of excess of the nominal wear coefficient of the right tamping unit, it is necessary to carry out detailed diagnostics of the drive of the right tamping unit. It is necessary to start with a safety valve, since, according to statistics, valves account for more than $70 \%$ of hydraulic equipment malfunctions. 


\section{Conclusion}

As a result of the work performed, it can be said that the indications of the developed software and hardware complex allow assessing the current technical condition of the tamping units and can be used to form the plan for maintenance and repair of track machines. At the same time, it is necessary to organize the accumulation of statistical information on various units and components of machines for the future implementation of the function of predicting the onset of pre-failure state.

To reduce the costs associated with equipping with the monitoring system for the technical condition of track machines, work is planned for 2018-2019 to combine the functionality of the automated monitoring system for special rolling stock (AS MWPSRS) [8] developed by "NIAC" of JSC "VNIIZhT" (Railway Research Institute) and the monitoring system for technical condition developed by specialists of the Siberian State Transport University.

\section{References}

1. A.L. Manakov, S.A. Kolarzh, Transport of the Urals 1(52), 57 - 60 (2017)

2. A.Yu. Kirpichnikov, Ensuring the reliability of technical operation of machinery parks in transport construction, thesis (Novosibirsk, 2013)

3. A.L. Manakov, A.A. Igumnov, S.A. Kolarzh, FTPRPI 4, 125-132 (2013)

4. A.L. Manakov, Vestnik RGUPS (The Bulletin of the RSTU), 109-117 (2013)

5. D. Dorotova, Gudok.ru, Transsib 5 (2018) http://www.gudok.ru/zdr/180 $/ ? \mathrm{ID}=1404073 \&$ archive $=45814 \mathrm{~s}$

6. S.A. Kolarzh, A.A. Igumnov, Materials of the IX International Scientific and Technical Conference "Polytransport Systems", 387-390 (2017)

7. J. Fischer, Einfluss von Frequenz und Amplitude auf die Stabilisierung von Oberbauschotter, Dissertation (Technische Universitat Graz, 1983)

8. V. Gorelkin, Gudok $206 \quad$ (26111) (2016) http://www.gudok.ru/ newspaper/?ID=1356474 